\title{
Trombosis Masiva Aguda de la Arteria Ovárica en el Puerperio
}

\author{
(Presentación de un Caso) \\ Dr. Arturo Rodríguez Soto *
}

La trombosis de las arterias pélvicas es una complicación extraordinariamente rara, a diferencia de las trombosis venosas.

Esta comunicación tiene por objeto presentar un caso de trombosis masiva aguda de la arteria ovárica en el puerperio. En la revisión de la literatura médica reciente, no hemos encontrado ringún caso de este tipo.

Austin (1) describe un caso de tromboflebitis masiva de la vena ovárica, en el puerperio.

Burns, (2) en un estudio de 8.012 pacientes obstétricas, encuentra 36 casos de tromboembolias venosas en el puerperio, pero ningún caso de trombosis arterial.

En la génesis de la trombosis puerperal se consideran tres mecanismos principales: a) Estasis venosa. b) Alteración de la pared vascular. c) Alteraciones fisioquímicas de la sangre. (3)

Algunos autores (4) agregan un factor neurovegetativo, inestable especialmente en la embarazada que va a producir vasoespasmos, edema y anoxia de la pared venosa.

Se admite en general que las trombosis venosas no tienen relación con las manifestaciones infecciosas del puerperio, pero en cambio predisponen a su aparición las maniobras intrauterinas (versión interna, alumbramiento manual, expresión uterina etc.) (5).

\section{CASO REPORTADO - HISTORIA CLINICA} horas.

Nombre: M. F. Edad: 21 años. Fecha de Ingreso: 13 de Octubre 1961. 19

* Del Departamento de Ginecología del Hospital de San Juan de Dios. Bogotá. 
Causa de Consulta: Dolor abdominal intenso localizado en F. I. D. Náuseas y vómito. Hemorragia vaginal. Sintomatología iniciada en el $3^{\text {o }}$ día del puerperio.

Antecedentes ginecológicos: Menarquia 12 años. Ciclos 30 × 3-4. Dismenorrea ocasional premenstrual.

Antecedentes Obstétricos: G5P5A1. Embarazos y partos normales. Ultimo parto 9 de Octubre de 1961.

Enfermedad Actual: Se remonta a su último parto verificado el 9 de Octubre; parto gemelar a término atendido en una entidad oficial. Duración del trabajo 4 horas Anestesia con gases en el período expulsivo. Aplicación de ocitocina en el puerperio inmediato. Deambulación en el $2^{\circ}$ día del puerperio. La enferma salic de la clínica el 12 de Octubre en las horas de la tarde. Anota que en la mañana de este día se le hizo expresión del fondo uterino para extraer coágulos.

A las 21 horas del 12 de Octubre, inició dolor en F. I. D. que se fue haciendo progresivamente intenso y que se irradiaba a epigastrio y región lumbar derecha; presentaba náuseas, vómito y hemorragia vaginal en regular cantidad. En estas condiciones ingresa al servicio de pensionados del Hospital de San José de Bogotá.

Examen Físico: Paciente en buenas condiciones generales. Temperatura bucal $37.3^{\circ}$ temperatura rectal $37.7^{\circ}$ T. A. $12 \times 8$. Pulso $92 \times 1$ '. Senos turgentes con abundante secreción láctea. Corazón: ruidos cardíacos normales. Pulmones clínicamente normales.

Abdomen: Defensa y contractura abdominal en F. I. D. Blumberg positivo. Dolor a la palpación en región lumbar derecha. El útero se palpa a unos 12 cms. por encima del pubis y su consistencia es dura.

Genitales: Vello pubiano rasurado. Uretrocistocele II. Rectocele I. Desgarro perineal I. Se aprecia sangre de color negruzco en el introito.

Tacto: B. S. U. normales. Vagina de paredes normales. Cuello posterior, blando, con orificio cervical externo e interno con dilatación de $3 \mathrm{cms}$. El útero se palpa de un tamaño aproximado de $14 \mathrm{cms}$. en su diámetro vertical, su consistencia es dura. Hay dolor intenso en fondo de saco derecho pero no se aprecia ninguna tumoración. Fondo de saco izquierdo libre, no doloroso.

Cuadro Hemático: Octubre 13. 191/2 horas.

Hematíes: 4.620.000. Leucocitos: 12.600. Hemoglobina: 14 Grms.

Neutrófilos: 55. Eosinófilos: 1. Basófilos: 0. Linfocitos: 42. Monocitos: 2.

Sedimentación: $1 / 2$ hora: $10 \mathrm{~mm}$. 1 hora: $18 \mathrm{~mm}$.

Con diagnóstico de presunción de apendicitis aguda o hematoma de ligamento ancho se interviene.

Descripción Quirúrgica: Se practica examen bajo anestesia y se encuentran restos placentarios en cavidad uterina que se extraen. No se palpa ninguna tumoración en fondos de saco. 
Se hace incisión pararectal derecha infraumbilical. Se explora cavidad abdominal encontrando el útero globuloso de aproximadamente $12 \mathrm{cms}$. y de consistencia dura. Escaso líquicic serosanguinolento en la región pélvica. La trompa y el ovario derecho se encuentran de color rojo oscuro con áreas hemorrágicas que se extienden por todo el ligamento ancho. A la palpación se aprecia un cordón de consistencia dura, cilíndrico, de unos $3 \mathrm{cms}$. en su diámetro mayor que parte del hilio ovárico, atraviesa el ligamento ancho y continúa por debajo del peritoneo parietal, inmediatamente por encima de los vesos ilíacos, y llega hasta la aorta.

Se abre el peritoneo parietal posterior y se encuentra la arteria ovárica trombosada, se abre longitudinalmente y se extrae un trombo perfectamente organizado que se extiende a todo lo largo del vaso. Se diseca la arteria hasta cerca a su nacimiento en la aorta, se practica ligadura y extirpación del vaso. No se evidencia trombo por encima de la ligadura. El ovario y la trompa muestran zonas extensas de hemorragia y necrosis. Se practica salpingooforectomía derecha y apendicectomía profiláctica.

El postoperatorio fue enteramente normal. Se practicaron pruebas de coagulabilidad sanguinea las cuales fueron normales; se hizo tratamiento anticoagulante preventivo.

Informe Anatomopatológico No E 712-61. Laboratorio Santiago Samper. Hospital de San Juan de Dios.

Descripción Macroscópica: Se recibe una trompa y un ovario marcados derechos. La trompa mide $6 \mathrm{cms}$. por $1,5 \mathrm{cms}$. El ovario $3 \mathrm{cms}$. en su diámetro máximo. La trompa muestra por su parte externa tejido fibroso y material de color rojo claro irregularmente distribuído. Al corte está aumentada de consistencia y deja ver unas paredes engrosadas y su luz ocupada por un material de color café claro. El ovario presenta una superficie externa lisa, brillante con extensas áreas hemorrágicas. Al corte es de consistencia blanda, friable, en él se ven numerosos quistes foliculares, que varían de 0,1 cms. a $0.4 \mathrm{cms}$. Se ve un cuerpo amarillo de $0,7 \mathrm{cms}$. Se recibe además un tejido marcado arteria ovárica de aspecto cilíndrico que mide $12 \mathrm{cms}$. de longitud por $0,4 \mathrm{cms}$. de diámetro. Al corte está aumentado de consistencia y muestra una luz ocupada por un material de aspecto sanguinolento, de color rojo oscuro, rodeado por una pequeña banda de tejido de color amarillo claro.

Descripción Microscópica: Los cortes muestran ova:io, trompa y apéndice. El ovario muestra abundantes quistes foliculares, folículos primordiales y un cuerpo amarillo con signos de regresión. La trompa muestra congestión y áreas de hemorragia de las peredes. Muy cerca se observa una arteria de mediano calibre con un trombo organizado en su interior. El apéndice vermiforme no muestra alteraciones.

Diagnóstico: Salpingooforectomía derecha por trombosis de arteria ovárica. Apéndice cecal. 


\section{COMENTARIO}

Se presenta un caso de trombosis aguda masiva de la arteria ovárica derecha en el puerperio. La literatura médica reciente no reporta ningún caso de esta clase; se practicó trombectomía, extirpación de la arteria ovárica derecha y salpingooforectomía derecha.

En cuanto a la etiología de esta trombosis la atribuímos a traumatismo vascular con alteración de la pared y aglutinación masiva de los elementos de la sangre, origen del trombo, causada por traumatismo del fondo uterino y de la región parauterina derecha.

Consideramos que deben ser proscritas de la obstetricia estas maniobras que causan daño en las paredes vasculares y que van a producir complicaciones tan graves como la descrita.

\section{BIBLIOGRAFIA}

1 AUSTIN. O. G.: Massive thromboflebitis of the ovarian vein. Am. J. Obst. \& Gynec. 72 : $428,1956$.

2 BURNS, W. T.: Thromboembolic disease in obstetrics and gynecology. Am. J. Obst. \& Gynec. 72: 260, 1956.

3 QUIJANO, M. Y NOBLE, L.: Algunas consideraciones acerca de las trombosis venosas y embolias pulmonares. Ginec. Tbst. Mex. 14: 215, 1959.

4 MORINET, P. et CHOUKRON, J.: Les throbophlebites puerperales. Presse med. 68 : 2185,1960 .

5 LEON, J.: Tratado de Obstetricia. Volumen III Pág. 1.236. Editorial Científica Argentina. Buenos Aires. 1959. 